their approach despite their caution to screen for diabetes mellitus. They referred to it as a "clinical disaster area."

The reasons for this conclusion seem to be that Masters and Johnson overlooked important factors -somatic, pharmacological, and psychological. Roger S Kirby draws attention to the main somatic factors contributing to erectile dysfunction, including the better recognition of a basis in vascular disease. ${ }^{2}$ Of the pharmacological factors, the main omission from the list is cimetidine. ${ }^{3}$

The other main factor, overlooked by Masters and Johnson and not considered by Kirby, is depression. "Depression" covers a multitude of concepts, including the low self esteem and demoralisation that may result from sexual dysfunction. The biogenic form of the mood disorder, which may be expected to improve with prescription of antidepressants, is characterised by a lowering of hedonic tone, the loss of pleasure and interest pervading every aspect of a person's life, including sexual arousal. Lack of recognition of the mood disorder may lead to focus on the sexual dysfunction, and it may be this that leads to a request for advice and treatment. Consideration of both psychotherapy and physical treatments must be deferred until the mood state has resolved. A simple self assessment mood disorder scale, the hospital anxiety and depression scale, ${ }^{4}$ is readily completed in clinic waiting areas or at the time of the consultation; the depression subscale focuses on the loss of pleasure response-that is, the biogenic form of the mood disorder. The scale is provided with clear indications for interpreting the scores and chart to assess progress. The scale should be used routinely in sexual dysfunction clinics; it is available from NFER-Nelson, Darville House, 2 Oxford Road East, Windsor, Berkshire SL4 1DF.

Academic Unit of Psychiatry, St James's University Hospital, Leeds LS9 7TF

1 Masters WH, Johnson VE. Human sexual inadequacy. Boston: Little, Brown, 1970 .

2 Kirby RS. Impotence: diagnosis and management of male erectile dysfunction. $B M 7$ 1994;308:957-61. (9 April.)

3 Peden NR, Cargill JM, Browning MCK, Saunders JHB, Wormsley KG. Male sexual dysfunction during treatment with Wormsley KG. Male sexual dyst
cimetidine. BMf 1979;:659.

4 Zigmond AS, Snaith RP. The hospital anxiety and depression rating scale. Acta Psychiatr Scand 1983;67:361-70.

\section{Training in psychosexual medicine}

EDITOR,-As a founder member of the Institute of Psychosexual Medicine who began my own psychosexual training briefly with Balint and then with Tom Main, I read with interest the account of the institute's current method of training and of its valiant attempt to assess it, a notoriously difficult exercise. ${ }^{1}$ I was, however, surprised to learn that the institute adheres rigidly to some of the rules laid down in those early days and has not moved to a more eclectic approach as I and most other therapists in this country and around the world have done.

In particular, I was astonished to read that it still does not encourage partners to attend. One of the essential skills in this kind of work is the ability to improve communication between partners. Changing the attitude of one partner, who may be quite unable to impart these new insights to the other, is liable to be more destructive than therapeutic to the total relationship. I have always encouraged the presenting patient to persuade his or her partner to join in therapy.

Training in seminars is, however, valuable. Meeting regularly in a small group helps the therapist to share the anxieties we all feel when

beginning to work with patients, and blind spots are soon exposed by colleagues.

Seminars have been used as part of training both in the course I began in Manchester in 1980 and in most of the training schemes now running in centres throughout the country under the auspices of the British Association of Sexual and Marital Therapists. ${ }^{2}$ These courses are all multidisciplinary, and I have learnt a great deal from colleagues in other disciplines, whose collaboration I have valued both in training and in therapy. I think that the institute has suffered in restricting its training to medical practitioners.

Seminars are a good way of introducing doctors to the techniques of counselling, which are still not taught well in most medical schools. They can also increase doctors' skills in treating patients who present with sexual problems in their surgery or family planning clinic. If, however, these doctors wish to be accredited for work in psychosexual clinics the institute should adopt broader, more eclectic, and ideally multidisciplinary training methods.

MAY DUDDLE

Carnforth, Consultant psychir

Lancashire LA5 0TP

1 Mathers N, Bramley M, Draper K, Spread S, Tobert A. Assessment of training in psychosexual medicine. BMF 1994; 308:969-72. (9 April.)

2 Stanley S, Kellett J, Falkowski M, Ramage M, Sketchley J. St George's Hospital Medical School course for the diploma in human sexuality. Sexual and Marital Therapy 1986;1:75-88.

\section{Teaching medical students about disability}

EdrToR,-Alleyna Claxton rightly emphasises that medical education on the special needs of disabled people should start with undergraduates. ${ }^{1}$ But we need to decide what undergraduates need to know and how that knowledge should be imparted. Furthermore, because students learn much in medical schools that is instantly forgotten once the exams are over we need to show that doctors have a positive role in their work with disabled people, so that at least some of what is learnt is likely to be retained.

The most important message to impart is that the traditional model of diagnosis-treatmentcure is mostly inappropriate when dealing with disabled people. A cure (for the disability) is almost never likely, but that does not mean that doctors have no role. Take visual impairment as a model: less than a quarter of people who have severe visual impairment over the age of 60 are registered as either partially sighted or blind. ${ }^{2}$ This is a failure by doctors in the community to identify patients and also by medical staff in hospitals to register patients attending eye clinics. According to the prevailing medical and lay view, this hardly matters for registration is seen as a negative act of dubious benefit, resulting only in labelling and stigmatism. Nothing could be further from the truth, for the Royal National Institute for the Blind has shown that registration is the trigger for multidisciplinary support, ${ }^{2}$ recently exhorted by the Department of Health. ${ }^{3}$ By not appreciating the importance of registration doctors are unwittingly, yet significantly, limiting patients' quality of life.

Further examples from other types of disability would have a similar message: the doctor is the key to identification and subsequently to unlocking a range of facilities and services, many perhaps outside the NHS, that can help to improve the quality of life of individual disabled people.

Disability medicine is indeed "whole person medicine" and requires good communication skills. Even today communication skills are far from ideal: many parents of children with visual impairment want to talk to but cannot find someone who is knowledgeable about the condition, and $80 \%$ want better communication and more information, particularly on medical matters. ${ }^{4}$ Understanding the functional aspects of impairment is complex. According to one blind man, "my ophthalmologist tells me what I can see, but it doesn't bear much relation to what I can do." Simulation helps. Although only a limited range of disabilities can be simulated, perhaps the most valuable lesson for students is how the attitude of ordinary people towards them changes when they are placed in wheelchairs or given white sticks.

How best to impart the requisite knowledge and the appropriate attitudes can be argued about indefinitely. Probably no single method is appropriate for all medical schools as local families and traditions vary widely. We welcome the publication of Medical Education on Disability ${ }^{5}$ as a starting point offering ideas on both content and methodas Claxton says, just the stuff of the core medical curriculum.

ALISTAIR R FIELDER
Birmingham and Midland Eye Hospital,
Birmingham B3 2NS

IM MARSHALL

Department of Public Health and Epidemiology,

Senior lecturer

Birmingham B15 2TT

1 Claxton A. Teaching medical students about disability. $B M$ 1994;308:805. (26 March.)

2 Bruce I, McKennell A, Walker E. Blind and partially sighted adults in Britain: the RNIB survey. London: HMSO, 1991.

3 Tyrell R. Letter to directors of social service departments, managers of district health authorities and chief executives of hospital trusts. London: Department of Health, February 1994.

4 Walker E, Tobin M, McKennell A. Blind and partially sighted children in Britain: the RNIB survey. Vol 2. London: HMSO, 1992.

5 Inman C, Kahtan S. Medical education on disability: a repon from University College London Medical School and the Prince of Wales' Advisory Group on Disability, London: University College London Medical School, 1993.

\section{Sexual revolution and sperm count}

EDITOR,-Together with other discoveries, the findings of Carlsen et al that the quality of semen has been declining over the past 50 years ${ }^{1}$ have led to disturbing speculation about the world's environment. I think, however, that the relation of their findings to such speculation is scientifically untenable.

Given the criteria for semen quality used by Carlsen et al, the findings suggest merely a general dilution of semen caused by more frequent ejaculation of men today compared with $\mathbf{5 0}$ years ago. But their conclusion-that "such remarkable changes in semen quality ... over a relatively short period is more probably due to environmental rather than genetic factors"-is not so trivial.

They justify this conclusion with two statements that, on closer inspection, are unscientific. Firstly, ". . . to our knowledge there are no data to indicate a change in masturbation or coital frequency since the 1930 s." There are no reliable data on masturbation or coital frequency whatsoever, neither for the 1930 s nor for the 1990 s. It is not justified to conclude from this lack of knowledge that there has been no change.

Secondly, "... 32 papers contain information on the prescribed length of abstinence, which was at least three days, as generally recommended by andrologists throughout the past 50 years." This means that in the 29 other papers reviewed the period of abstinence was not mentioned. This is understandable: it is naive for an investigator to expect that perfectly healthy men (one of the inclusion criteria for this review) will refrain from sexual activity for at least three days to perform a 